\title{
Inorganic Hierarchical Nanostructures Induced by Concentration Difference and Gradient
}

\author{
Haibin Chu, Xuemei Li, Guangda Chen, Zhong Jin, Yan Zhang, and Yan Li $(\bowtie)$ \\ Beijing National Laboratory for Molecular Sciences, Key Laboratory for the Physics and Chemistry of Nanodevices, National \\ Laboratory of Rare Earth Material Chemistry and Application, College of Chemistry and Molecular Engineering, Peking University, \\ Beijing 100871, China \\ Received: 18 April 2008/ Revised: 11 July 2008/Accepted: 11 July 2008 \\ CTsinghua Press and Springer-Verlag 2008. This article is published with open access at Springerlink.com
}

\begin{abstract}
A very simple strategy for preparing hierarchical inorganic nanostructures under ambient aqueous conditions is presented. The hierarchical inorganic nanomaterials were obtained by simply adding a highly concentrated solution of one reactant to a solution of another reactant with low concentration. No surface-capping molecules or structure-directing templates were needed. The preparation of hierarchical single crystalline $\mathrm{PbMoO}_{4}$ was used as an example in order to study the effects of varying the reaction conditions and the mechanism of the process. It was found that the large concentration difference (typically in excess of 200-fold) and the concentration gradient of the reactants both play key roles in controlling the diffusion process and the morphology of the resulting nanostructures. This kinetically controlled strategy is facile and is easily adapted to prepare a variety of inorganic materials.
\end{abstract}

\section{KEYWORDS}

Crystal growth, hierarchical, nanostructures, kinetics

\section{Introduction}

Recently, hierarchical inorganic nanomaterials with complex structures have attracted much attention due to their distinct characteristics and potential applications [1-7]. Bottom-up approaches have great potential for fabrication of such nanostructures. Methods based on the vapor-liquid-solid (VLS) mechanism were pioneered in preparing hierarchical inorganic nanomaterials [8-13]. Later, fabrication of hierarchical inorganic nanomaterials was carried out via vapor transfer and condensation [1, 14-17]. All the above methods need relatively high temperatures $\left(>400{ }^{\circ} \mathrm{C}\right)$, however. Solvothermal processes $[5,18$
23] or reactions in nonaqueous solutions involving capping agents $[24,25]$ offer other ways to synthesize hierarchical inorganic nanomaterials at moderate temperatures (typically $>100{ }^{\circ} \mathrm{C}$ ). Alternatively, ultrasonic [26] or microwave radiation [27] have been used to assist the formation of branched structures. Aqueous-phase chemical synthesis under ambient conditions has been considered as a potential promising route because of its low energy requirements, safe and environmentally benign processing conditions, and the potential for large-scale production. However, surface-capping reagents are often needed in such processes [28-33]. The development of simple and general synthetic

Address correspondence to yanli@pku.edu.cn

\section{Springer}


approaches for building hierarchical architectures under ambient aqueous conditions remains a significant challenge.

Bio-inspired approaches [34] have highlighted another way to control the nucleation, polymorphism, and growth of crystals under ambient conditions during mineral formation, in which kinetic control by diffusion is rather important [35-37]. Encouraged by these natural processes, we tried to make use of diffusion controlled processes under ambient conditions to produce hierarchical nanostructures. In this paper we describe a simple way of preparing hierarchical nanomaterials by adding a highly concentrated solution of one reactant to a solution of another reactant with low concentration under ambient conditions without the surface-capping molecules or structure-directing templates. We systematically studied the process by using the preparation of dendritic $\mathrm{PbMoO}_{4}$ nanocrystals as an example. This synthetic approach can be extended to other hierarchical inorganic nanomaterials, such as $\mathrm{PbS}, \mathrm{SrC}_{2} \mathrm{O}_{4}$, and $\mathrm{Zn}(\mathrm{OH})_{2}$, and offers a potential general method for the synthesis of such materials. Although millimeter to micrometer sized hierarchical crystals have been prepared by traditional counterdiffusion methods in gels or different reservoirs [38$41]$, the processes normally require reaction over a few days [38-40]. Compared with these methods, our strategy is a simple, clean, and quick way to obtain hierarchical nanocrystals.

\section{Experimental}

Two different processes were used to synthesize dendritic $\mathrm{PbMoO}_{4}$ nanocrystals, i.e., the $\mathrm{Pb} /$ Mo route and the $\mathrm{Mo} / \mathrm{Pb}$ route. In a typical $\mathrm{Pb} / \mathrm{Mo}$ process, $\mathrm{Pb}(\mathrm{OAc})_{2} \cdot 3 \mathrm{H}_{2} \mathrm{O}$ powder $(0.076 \mathrm{~g}, 0.20 \mathrm{mmol})$ or $1.0 \mathrm{~mL}$ of $1.5 \mathrm{~mol} / \mathrm{L} \mathrm{Pb}(\mathrm{OAc})_{2}$ solution was added to $20 \mathrm{~mL}$ of $1.0 \mathrm{mmol} / \mathrm{L} \mathrm{Na}_{2} \mathrm{MoO}_{4}$ solution without agitation at room temperature. After $15 \mathrm{~min}$, the resultant white precipitates were separated and washed with distilled water several times to remove the excess reactants and byproducts, and then dried in air. For the $\mathrm{Mo} / \mathrm{Pb}$ route, the synthesis procedure was identical to that for the $\mathrm{Pb} / \mathrm{Mo}$ route except that the feeding order of the two reactants was changed, i.e., $\mathrm{Na}_{2} \mathrm{MoO}_{4} \cdot 2 \mathrm{H}_{2} \mathrm{O}$
(0.048 g, $0.20 \mathrm{mmol})$ powder or $1.0 \mathrm{~mL}$ of $1.5 \mathrm{~mol} / \mathrm{L}$ $\mathrm{Na}_{2} \mathrm{MoO}_{4}$ solution was added to $20 \mathrm{~mL}$ of $1.0 \mathrm{mmol} / \mathrm{L}$ $\mathrm{Pb}(\mathrm{OAc})_{2}$ solution. Hierarchical star-shaped $\mathrm{PbS}$ nanocrystals, $\mathrm{SrC}_{2} \mathrm{O}_{4}$ microcrystals, and flowerlike $\mathrm{Zn}(\mathrm{OH})_{2}$ nanostructures were prepared by similar methods. The detailed synthesis procedures are given in the Electronic Supplementary Material (ESM).

The resulting products were characterized by scanning electron microscopy (SEM) (FEI XL30 S-FEG), transmission electron microscopy (TEM) (JEOL, JEM-200CX), X-ray diffraction (XRD) (Rigaku Dmax-2000 with $\mathrm{Cu} \mathrm{K} \alpha$ radiation, $\lambda=1.5406 \AA$ ), highresolution TEM (HRTEM) (FEI Tecnai F30), X-ray photoelectron spectroscopy (XPS) (Kratos Axis Ultra), atomic force microscopy (AFM) (Seiko Instruments Inc., SPA400 SPM), and infrared (IR) spectroscopy (Nicolet Magna-IR 750 spectrometer).

\section{Results and discussion}

Figure 1 shows typical TEM and SEM images of the hierarchical $\mathrm{PbMoO}_{4}$ product obtained by the $\mathrm{Pb} /$ Mo route. All the as-synthesized $\mathrm{PbMoO}_{4}$ materials possessed a dendritic structure [21], with most of the dendrites having four branches pointing towards the four vertices of a square. Leaflets perpendicular to the trunks were found on the longer branches, whereas shorter branches were bald without leaflets. By examining more than 100 dendrites by SEM or TEM, it was found that the bald dendrites had a branch length of 35-135 nm whilst branches with a length of 160-445 nm normally had leaflets of $10-40 \mathrm{~nm}$ in width. The XRD pattern of the dendritic nanocrystals (Fig. 1(d)) shows strong and sharp diffraction peaks corresponding to $\mathrm{PbMoO}_{4}$ with a body-centered tetragonal scheelite structure (JCPDS 77-0431), and no byproduct peaks were observed. The relative intensity of the $\{004\}$ to $\{200\}$ reflections is 0.98 , which is much larger than that found in isotropic bulk crystals $\left(I_{\{004\}} / I_{\{200\}}=0.60\right.$ in JCPDS 77-0431). This indicates that the dendritic nanocrystals grew along the $\langle 100\rangle$ directions.

To provide further insight into the structures of the hierarchical dendrites, HRTEM investigations were performed. HRTEM images recorded from the branch, the leaflet, and the connecting region 


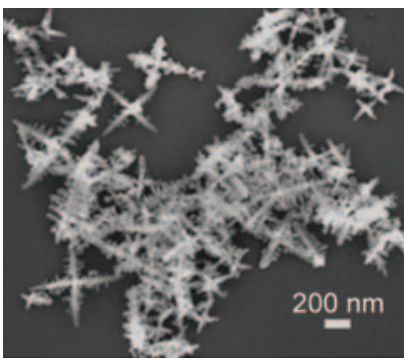

(a)

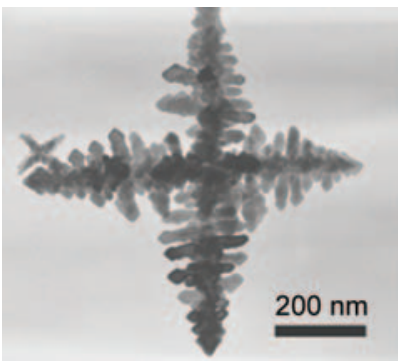

(c)

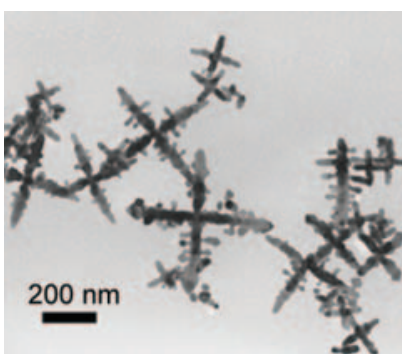

(b)

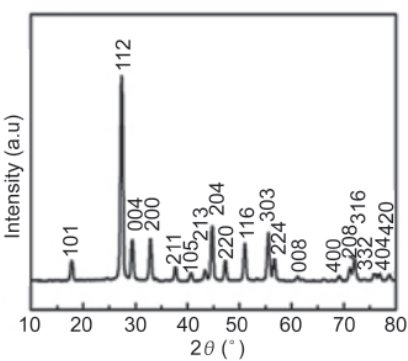

(d)
Figure 1 SEM (a) and TEM (b), (c) images and XRD pattern (d) of the $\mathrm{PbMoO}_{4}$ product obtained by adding $0.20 \mathrm{mmol}$ of $\mathrm{Pb}(\mathrm{OAc})_{2} \cdot 3 \mathrm{H}_{2} \mathrm{O}$ powder to $20 \mathrm{~mL}$ of $1.0 \mathrm{mmol} / \mathrm{L} \mathrm{Na} \mathrm{MoO}_{4}$ solution without agitation at room temperature

between the branch and the leaflet indicated that each $\mathrm{PbMoO}_{4}$ dendrite was a single crystal (Fig. 2). The observed lattice fringe distances of the three selected areas were all $0.272 \mathrm{~nm}$, equal to the (200) spacing of scheelite $\mathrm{PbMoO}_{4}$. Fast Fourier transform images showed that the upper left branch extended along the [010] direction (Fig. 2(b)), whilst the leaflets on this branch grew along the [100] (Fig. 2(c)) or [100] direction (Fig. 2(d)). It seems that the $\mathrm{PbMoO}_{4}$ crystals grew along four $\langle 100\rangle$ directions to form the fourarmed bald dendrites and subsequent growth of the leaflets out of the branches afforded the hierarchical dendrites.

We systematically studied the effect of varying the reactant concentrations on the morphology of the resultant $\mathrm{PbMoO}_{4}$ crystals. Typically, the $\mathrm{Mo} /$ $\mathrm{Pb}$ route could also produce hierarchical dendritic $\mathrm{PbMoO}_{4}$ nanocrystals (Fig. 3(a) and Fig. S-1 in the ESM). However, if we added $20 \mathrm{~mL}$ of $\mathrm{Pb}(\mathrm{OAc})_{2}$ solution with concentration of $1.0 \mathrm{mmol} / \mathrm{L}$ to 20 $\mathrm{mL}$ of equimolar $\mathrm{Na}_{2} \mathrm{MoO}_{4}$ solution, irregular nanoparticles comprised the majority of the product (Fig. 3(b)). Further investigation indicated that a low concentration of one reactant and a high concentration of the other reactant were necessary for the synthesis of hierarchical $\mathrm{PbMoO}_{4}$ nanocrystals

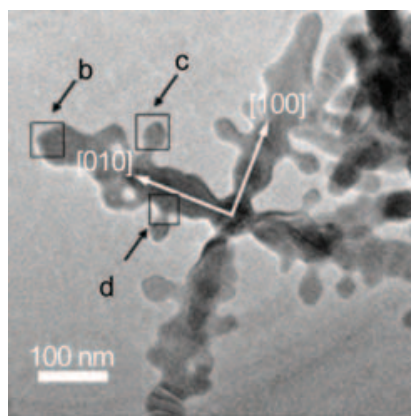

(a)

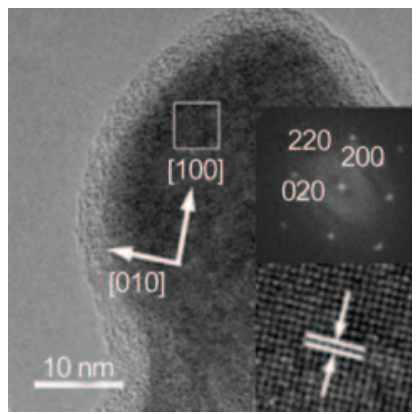

(c)

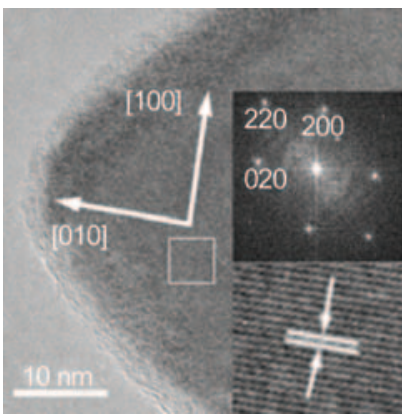

(b)

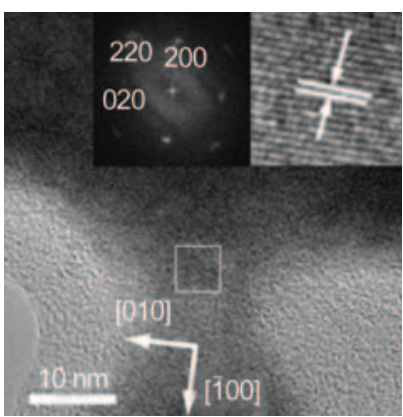

(d)
Figure 2 (a) TEM image of an individual $\mathrm{PbMoO}_{4}$ nanodendrite; (b)-(d) HRTEM images taken from the branch, leaflet, and the junction of the branch and leaflet, respectively, as marked in (a). The corresponding insets show the fast Fourier transform and the lattice images from the specified square areas. The lattice fringe space is $0.272 \mathrm{~nm}$

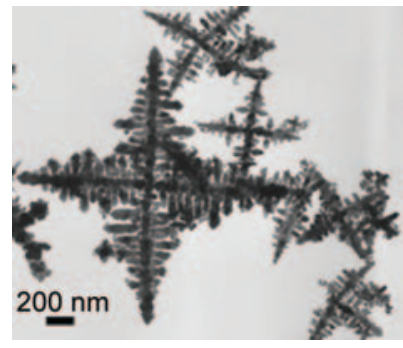

(a)

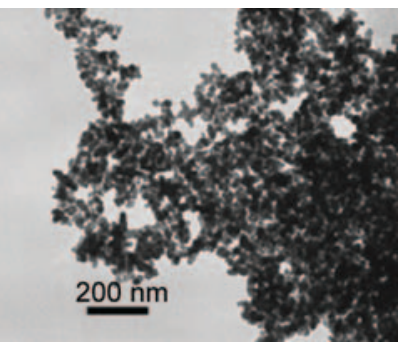

(c)

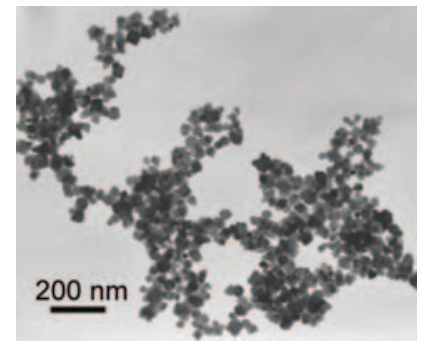

(b)

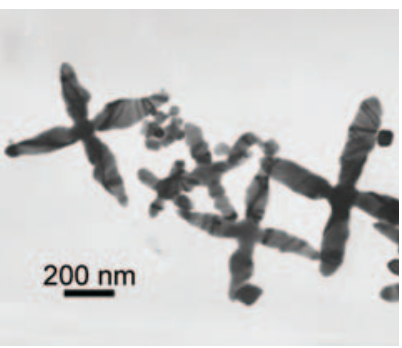

(d)
Figure 3 TEM images of the $\mathrm{PbMoO}_{4}$ nanocrystals obtained under different conditions: (a) $1.0 \mathrm{~mL}$ of $1.5 \mathrm{~mol} / \mathrm{L} \mathrm{Na}_{2} \mathrm{MoO}_{4}$ solution was added to $20 \mathrm{~mL}$ of $1.0 \mathrm{mmol} / \mathrm{L} \mathrm{Pb}(\mathrm{OAc})_{2}$ solution ( $\mathrm{Mo} / \mathrm{Pb}$ route) without agitation at room temperature; (b) $20 \mathrm{~mL}$ of $1.0 \mathrm{mmol} / \mathrm{L}$ $\mathrm{Pb}(\mathrm{OAc})_{2}$ solution was added to $20 \mathrm{~mL}$ of $1.0 \mathrm{mmol} / \mathrm{L} \mathrm{Na} \mathrm{MoO}_{4}$ solution without agitation at room temperature; (c) $0.20 \mathrm{mmol}$ of $\mathrm{Pb}(\mathrm{OAc})_{2} \cdot 3 \mathrm{H}_{2} \mathrm{O}$ powder was added to $20 \mathrm{~mL}$ of $1.0 \mathrm{mmol} / \mathrm{L} \mathrm{Na}_{2} \mathrm{MoO}_{4}$ solution ( $\mathrm{Pb} / \mathrm{Mo}$ route) with stirring at room temperature; (d) $\mathrm{Pb} / \mathrm{Mo}$ route without agitation at $50^{\circ} \mathrm{C}$ 
in our system. The low concentration of one reactant plays an important role in the formation of dendritic $\mathrm{PbMoO}_{4}$ nanocrystals. For the $\mathrm{Pb} / \mathrm{Mo}$ route, $\mathrm{Na}_{2} \mathrm{MoO}_{4}$ concentrations in the range $0.25-4.0 \mathrm{mmol} / \mathrm{L}$ were suitable for the formation of dendritic $\mathrm{PbMoO}_{4}$ (Fig. S-2 in the ESM) whilst higher concentrations resulted in many irregular particles. The low concentration presumably leads to a slow diffusion rate of the reactant which is important for diffusioncontrolled crystal growth. The high concentration of the other reactant, $\mathrm{Pb}(\mathrm{OAc})_{2}$, is also important. It should be higher than $0.15 \mathrm{~mol} / \mathrm{L}$, or solid powders can be simply used as the reactant (Fig. 1 and Fig. S-3 in the ESM). An appropriate molar ratio of the two reactants was also found to be required in order to obtain the dendritic species as the major product. For the case of the $\mathrm{Mo} / \mathrm{Pb}$ route, a considerable excess of $\mathrm{Na}_{2} \mathrm{MoO}_{4}$ with respect to $\mathrm{Pb}(\mathrm{OAc})_{2}$ (e.g., $n_{\mathrm{Na}_{2} \mathrm{MoO}_{4}} /$ $\left.n_{\mathrm{Pb}(\mathrm{OAc})_{2}} \geqslant 5\right)$ was required in order to ensure the continual supply of a high concentration of $\mathrm{MoO}_{4}{ }^{2-}$ ions; otherwise, irregular particles of $\mathrm{PbMoO}_{4}$ were formed simultaneously (Fig. S-4 in the ESM).

The effects of stirring, varying temperature, and lead source were also investigated. When $\mathrm{Pb}(\mathrm{OAc})_{2} \cdot 3 \mathrm{H}_{2} \mathrm{O}$ powder was added to $\mathrm{Na}_{2} \mathrm{MoO}_{4}$ solution with stirring, the locally concentrated $\mathrm{Pb}^{2+}$ ions dispersed quickly throughout the whole solution, and thus the kinetically controlled crystal nucleation and growth could not take place (Fig. 3(c)). According to the diffusion equation $D=k T / f$ (where $D$ is the diffusion coefficient of the particle, $k$ is the Boltzmann constant, $T$ is the temperature, and $f$ is the resistance coefficient of the particle in solution), increasing the reaction temperature leads to an increase in the diffusion rate, which adversely affects the diffusioncontrolled crystal growth process. In this case, the high local concentration of $\mathrm{Pb}^{2+}$ ions dispersed quickly, and thus only bald dendrites of $\mathrm{PbMoO}_{4}$ without leaflets were obtained at $50{ }^{\circ} \mathrm{C}$ (Fig. 3(d)) and no branched crystals were obtained when the temperature was further increased. Besides $\mathrm{Pb}(\mathrm{OAc})_{2}$, other lead sources, such as $\mathrm{Pb}\left(\mathrm{NO}_{3}\right)_{2}$ and $\mathrm{Pb}\left(\mathrm{ClO}_{4}\right)_{2}$, also reacted with $\mathrm{Na}_{2} \mathrm{MoO}_{4}$ to produce dendritic $\mathrm{PbMoO}_{4}$ nanocrystals. This indicated that the presence of $\mathrm{OAc}^{-}$ions is not a prerequisite for the synthesis of the hierarchical $\mathrm{PbMoO}_{4}$ nanodendrites in our system.

In order to investigate the morphology evolution during the growth of the $\mathrm{PbMoO}_{4}$ dendritic nanostructures, we performed the synthesis using the $\mathrm{Mo} / \mathrm{Pb}$ route with different reaction times. The TEM images are shown in Figs. 4(a)-(c). At the very early stage of $1 \mathrm{~min}$, the products were mainly star-shaped $\mathrm{PbMoO}_{4}$ nanocrystals with four bald branches as shown in Fig. 4(a). The lengths of the branches were 130-190 $\mathrm{nm}$. When the reaction time was increased to $3 \mathrm{~min}$, the lengths of the branches increased to 360 $820 \mathrm{~nm}$ and some leaves started to grow out from the branches of the stars (Fig. 4(b)). When the reaction time was further prolonged, the length of the arms remained nearly constant but more leaves grew out from the branches to form the dendritic $\mathrm{PbMoO}_{4}$ nanocrystals with fully-grown leaves (Fig. 4(c)).

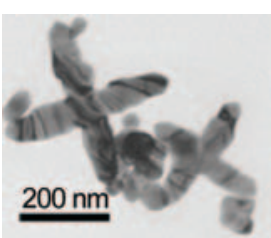

(a)

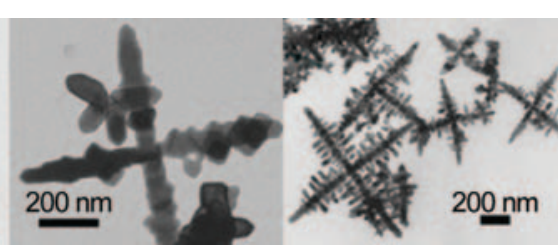

(b)

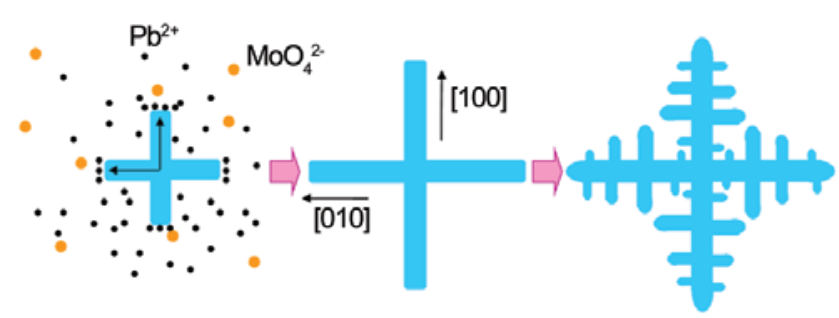

(d)

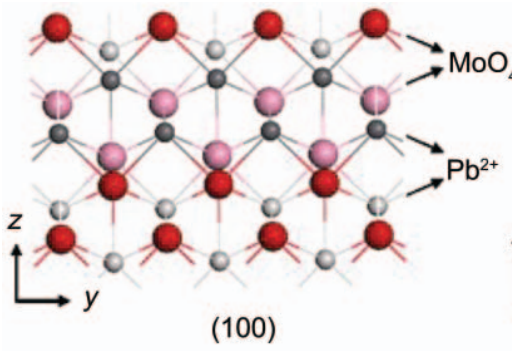

(e)

Figure 4 (a)-(c) TEM images of the $\mathrm{PbMoO}_{4}$ nanocrystals obtained via the $\mathrm{Mo} / \mathrm{Pb}$ route with different reaction times. (a) $1 \mathrm{~min}$; (b) $3 \mathrm{~min}$; (c) $15 \mathrm{~min}$.(d) Scheme showing the proposed formation mechanism of the hierarchical $\mathrm{PbMoO}_{4}$ nanodendrites by diffusioncontrolled fast growth along four $\langle 100\rangle$ directions and subsequent growth of the leaflets. (e) Crystalline structure projection on the (100) plane (left) and (001) plane (right). Only the uppermost two layers of ions are shown. The dark spheres represent the ions in the first layer and the light spheres represent the ions in the second layer. The adsorption capacity of $\mathrm{MoO}_{4}{ }^{2-}$ is higher on (100) than on (001) due to the lower coordination number of the $\mathrm{Pb}^{2+}$ cations 
Table 1 summarizes the atomic percentages of the surface elements measured by XPS for samples obtained by the $\mathrm{Pb} / \mathrm{Mo}$ and $\mathrm{Mo} / \mathrm{Pb}$ routes. The $\mathrm{Pb}$ : Mo ratio was higher on the surface of the product obtained by the $\mathrm{Pb} / \mathrm{Mo}$ route than that via the $\mathrm{Mo} / \mathrm{Pb}$ route. More importantly, no Na signal was detected in the $\mathrm{Pb} / \mathrm{Mo}$ product, whilst a high atomic percentage of $\mathrm{Na}$ was observed in the Mo/ $\mathrm{Pb}$ product. XPS results and IR spectra (Figs. S-5 and S-6 in the ESM) indicated that $\mathrm{OAc}^{-}$ions were present in both products. Therefore, the outermost surface layers of the $\mathrm{Pb} / \mathrm{Mo}$ product might consist of $\mathrm{Pb}^{2+}$ and $[\mathrm{Pb}(\mathrm{OAc})]^{+}$ions as the main adsorbates, while the $\mathrm{Na}^{+}$ions with a small amount of $\mathrm{OAc}^{-}$ions were adsorbed on the outermost surface layers of the $\mathrm{Mo} / \mathrm{Pb}$ products. Although some of the reactant species were adsorbed on the surface of $\mathrm{PbMoO}_{4}$ nanocrystals, the product was mainly composed of well-crystallized $\mathrm{PbMoO}_{4}$ as indicated by both the strong and sharp peaks in the XRD pattern (Fig. 1(d)) and the obvious lattice fringe in the HRTEM images (Fig. 2). Furthermore, the Mo $3 \mathrm{~d}_{3 / 2}$ peak at $235.19 \mathrm{eV}$ in the XPS spectrum of $\mathrm{PbMoO}_{4}$ nanocrystallites is consistent with the $\mathrm{Mo} 3 \mathrm{~d}_{3 / 2}$ peak of $\mathrm{Mo}(\mathrm{VI})$ in $\mathrm{MoO}_{4}{ }^{2-}$ $(235.1 \mathrm{eV})$.

Table 1 Surface composition of the products from the $\mathrm{Pb} / \mathrm{Mo}$ and $\mathrm{Mo} / \mathrm{Pb}$ routes

\begin{tabular}{ccc}
\hline \multirow{2}{*}{ Element } & \multicolumn{2}{c}{ Atomic percentage $(\%)$} \\
\cline { 2 - 3 } & $\mathrm{Pb} /$ Mo route & $\mathrm{Mo} / \mathrm{Pb}$ route \\
\hline $\mathrm{Pb}$ & 15.8 & 12.9 \\
$\mathrm{Mo}$ & 12.1 & 12.6 \\
$\mathrm{C}$ & 21.1 & 13.0 \\
$\mathrm{O}$ & 51.0 & 49.9 \\
$\mathrm{Na}$ & 0 & 11.6 \\
\hline
\end{tabular}

On the basis of the observed evolution of morphology with time, the surface composition, and the crystalline structure of the hierarchical $\mathrm{PbMoO}_{4}$ nanodendrites, a formation mechanism based on a diffusion-controlled process has been proposed as shown in Fig. 4(d). The crystal growth process can be divided into two stages: the formation of four branches and the growth of leaflets. For the case of $\mathrm{Pb} / \mathrm{Mo}$ route, by adding $\mathrm{Pb}(\mathrm{OAc})_{2}$ as a powder or concentrated solution, the concentrations of $\mathrm{Pb}^{2+}$ or $[\mathrm{Pb}(\mathrm{OAc})]^{+}$ions were rather high in local regions, which provided a large supersaturation favoring the formation of $\mathrm{PbMoO}_{4}$ nuclei. Furthermore, the high concentration of $\mathrm{Pb}^{2+}$ or $[\mathrm{Pb}(\mathrm{OAc})]^{+}$ions around a $\mathrm{PbMoO}_{4}$ nucleus also favors kinetic crystal growth. However, the concentration of $\mathrm{MoO}_{4}{ }^{2-}$ ions was relatively low around the $\mathrm{PbMoO}_{4}$ nucleus and also low in the regions far from the nucleation centers. Thus, the concentration gradient was small for $\mathrm{MoO}_{4}{ }^{2-}$ ions. According to Fick's first law [42], the diffusion rate of ions is proportional to the concentration gradient of the ions. Thus, $\mathrm{MoO}_{4}{ }^{2-}$ ions will diffuse only slowly into the $\mathrm{PbMoO}_{4}$ nucleation regions, which limits the crystal growth rate. The $\{100\}$ planes of scheelite $\mathrm{PbMoO}_{4}$, which have the most available coordination sites (Fig. 4(e)), grow fastest due to the preferential adsorption [43] of $\mathrm{MoO}_{4}{ }^{2-}$ ions. Eventually, the four arms grow along the four crystallographically equivalent $\langle 100\rangle$ directions to form the bald $\mathrm{PbMoO}_{4}$ nanodendrites. As growth continued, each branch could initiate further growth along $\pm[100]$ or $\pm[010]$ directions to form leaflets perpendicular to the branch. The leaflets grown in the second stage can also be related to the diffusioncontrolled crystal growth, while the excess $\mathrm{Pb}$ source provides large supersaturation locally around the $\mathrm{PbMoO}_{4}$ dendrites. The diffusion-controlled growth of the $\mathrm{PbMoO}_{4}$ nanodendrites is analogous in the $\mathrm{Mo} / \mathrm{Pb}$ route except that the crystal growth rate is limited by the slow diffusion of $\mathrm{Pb}^{2+}$ or $[\mathrm{Pb}(\mathrm{OAc})]^{+}$ ions instead of $\mathrm{MoO}_{4}{ }^{2-}$ ions. The electrostatic repulsion between $\mathrm{PbMoO}_{4}$ particles with like charges on the surface makes other growth modes, such as oriented attachment, less likely.

Diffusion-controlled processes are common in crystal growth. Not only single crystals of macroscopic size but also various kinds of nanocrystals can be obtained via such processes [35-40, 44-47]. However, our strategy based on the large concentration difference between two reactants offers an effective, simple, and convenient way to provide a diffusion-controlled crystal growth environment. The high concentration of one reactant provides the large supersaturation required for fast crystal nucleation and subsequent crystal growth. Two factors, the high local concentration of one reactant and the small concentration gradient of the other reactant, 
act together to give kinetic control over the crystal morphology. Our diffusion-controlled crystallization process is somewhat similar to diffusion-limited aggregation (DLA) processes, which are commonly seen in the formation of fractal patterns under farfrom-equilibrium conditions [48]. Since the 1980s, considerable attention has been paid to DLA mainly due to its importance in the morphological evolution of minerals in biological systems and biomimetic processes [49]. However, single crystals with strong anisotropy and low disorder like the hierarchical nanocrystals we prepared here have seldom been obtained via DLA processes [50].

Besides its simplicity, this strategy is potentially a general one and can be extended to the synthesis of many kinds of hierarchical inorganic materials. For example, hierarchical star-shaped PbS nanocrystals with short leaflets on the branches (Fig. 5(a)) and cubic phase were obtained by adding an excess of $\mathrm{Pb}(\mathrm{OAc})_{2} \cdot 3 \mathrm{H}_{2} \mathrm{O}$ powder to a thioacetamide solution of low concentration, hierarchical star-shaped $\mathrm{SrC}_{2} \mathrm{O}_{4}$

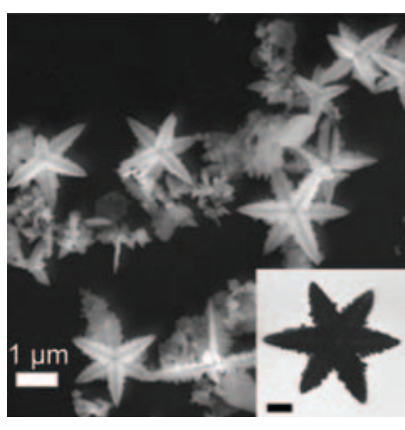

(a)

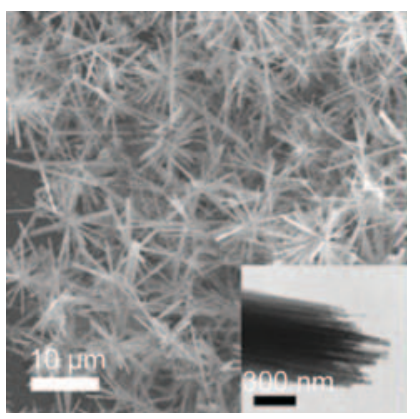

(c)

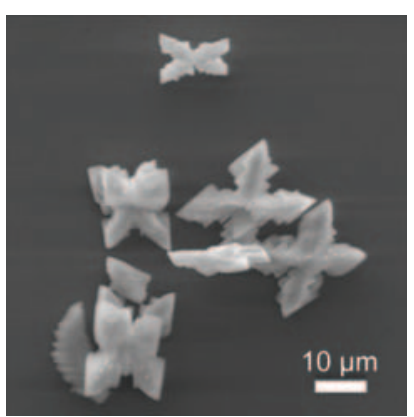

(b)

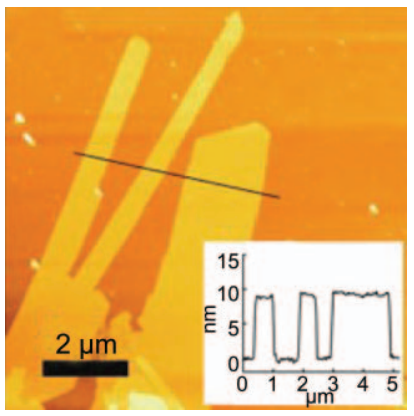

(d)
Figure 5 SEM, TEM, and AFM images of the hierarchical structures. (a) SEM image of star-shaped PbS nanocrystals with short leaflets on the branches as indicated in the TEM image inset; (b) SEM image of star-shaped $\mathrm{SrC}_{2} \mathrm{O}_{4}$ microcrystals with leaflets on branches; (c) SEM image of flowerlike $\mathrm{Zn}(\mathrm{OH})_{2}$ nanostructures with the TEM image inset showing that the branch consists of many nanobelts; (d) AFM image of the $\mathrm{Zn}(\mathrm{OH})_{2}$ nanobelts and the inset showing the section analysis microcrystals with leaflets on the branches (Fig. 5(b)) were obtained when a highly concentrated $\mathrm{SrCl}_{2}$ solution was added to dilute $\mathrm{Na}_{2} \mathrm{C}_{2} \mathrm{O}_{4}$ solution, and hierarchical flowerlike $\mathrm{Zn}(\mathrm{OH})_{2}$ nanostructures with hyperbranches composed of nanobelts could be obtained when a concentrated $\mathrm{NaOH}$ solution was added to a $\mathrm{Zn}(\mathrm{OAc})_{2}$ solution of low concentration (Figs. 5(c), (d)). Further data are given in the ESM.

\section{Conclusions}

Hierarchical inorganic nanostructures or microstructures were obtained by using a convenient aqueous-phase strategy under ambient conditions involving simply adding a highly concentrated solution of one reactant to a solution of the other reactant with low concentration. The high local concentration of the one reactant provides the thermodynamic conditions for crystal growth, and the extremely low concentration of the other reactant affords a diffusion-controlled kinetic environment for the heterogeneous growth of different crystalline faces, thus eventually inducing the formation of hierarchical nanocrystals. This method is very facile and can be adapted to many kinds of inorganic materials. Furthermore, it also might be extended to nonaqueous systems in order to produce hierarchical nanostructures of organic materials and polymers. Thus, this strategy may be a potential general route for fabricating various materials with hierarchical morphologies and different chemical compositions.

\section{Acknowledgements}

This work was supported by NSFC (Project 90406018) and the Ministry of Science and Technology (MOST) of China (Project 2007CB936202).

Electronic Supplementary Material: TEM and SEM images of products of comparative experiments, XPS results and IR spectra of $\mathrm{PbMoO}_{4}$, and XRD patterns of the hierarchical structures of $\mathrm{PbS}, \mathrm{SrC}_{2} \mathrm{O}_{4}$, and $\mathrm{Zn}(\mathrm{OH})_{2}$ are available in the online version of this article at http://dx.doi.org/10.1007/s12274-008-8024-5 and are accessible free of charge. 


\section{References}

[1] Yan, H. Q.; He, R. R.; Johnson, J.; Law, M.; Saykally, R. J.; Yang, P. D. Dendritic nanowire ultraviolet laser array. J. Am. Chem. Soc. 2003, 125, 4728-4729.

[2] Pan, Z. W.; Mahurin, S. M.; Dai, S.; Lowndes, D. H. Nanowire array gratings with $\mathrm{ZnO}$ combs. Nano Lett. 2005, 5, 723-727.

[3] Yin, L. W.; Bando, Y.; Zhu, Y. C.; Li, M. S.; Li, Y. B.; Golberg, D. Growth and field emission of hierarchical single-crystalline wurtzite AIN nanoarchitectures. Adv. Mater. 2005, 17, 110-114.

[4] Nehl, C. L.; Liao, H. W.; Hafner, J. H. Optical properties of star-shaped gold nanoparticles. Nano Lett. 2006, 6, 683688.

[5] Cao, M. H.; Liu, T. F.; Gao, S.; Sun, G. B.; Wu, X. L.; Hu, C. W.; Wang, Z. L. Single-crystal dendritic micro-pines of magnetic alpha- $\mathrm{Fe}_{2} \mathrm{O}_{3}$ : Large-scale synthesis, formation mechanism, and properties. Angew. Chem. Int. Ed. 2005, 44, 4197-4201.

[6] Huang, H. B.; Yang, S. G.; Gong, J. F.; Liu, H. W.; Duan, J. H.; Zhao, X. N.; Zhang, R.; Liu, Y. L.; Liu, Y. C. Controllable assembly of aligned $\mathrm{ZnO}$ nanowires/belts arrays. J. Phys. Chem. B 2005, 109, 20746-20750.

[7] Parfenov, A.; Gryczynski, I.; Malicka, J.; Geddes, C. D.; Lakowicz, J. R. Enhanced fluorescence from fluorophores on fractal silver surfaces. J. Phys. Chem. B 2003, 107, 8829-8833.

[8] Wang, Z. L.; Pan, Z. W. Junctions and networks of SnO nanoribbons. Adv. Mater. 2002, 14, 1029-1032.

[9] Dick, K. A.; Deppert, K.; Larsson, M. W.; Martensson, T.; Seifert, W.; Wallenberg, L. R.; Samuelson, L. Synthesis of branched "nanotrees" by controlled seeding of multiple branching events. Nat. Mater. 2004, 3, 380-384.

[10] Wang, D.; Qian, F.; Yang, C.; Zhong, Z. H.; Lieber, C. M. Rational growth of branched and hyperbranched nanowire structures. Nano Lett. 2004, 4, 871-874.

[11] Ge, J. P.; Li, Y. D. Selective atmospheric pressure chemical vapor deposition route to CdS arrays, nanowires, and nanocombs. Adv. Funct. Mater. 2004, 14, 157-162.

[12] May, S. J.; Zheng, J. G.; Wessels, B. W.; Lauhon, L. J. Dendritic nanowire growth mediated by a self-assembled catalyst. Adv. Mater. 2005, 17, 598-602.

[13] Lan, Z. H.; Liang, C. H.; Hsu, C. W.; Wu, C. T.; Lin, H. M.; Dhara, S.; Chen, K. H.; Chen, L. C.; Chen, C. C. Nanohomojunction $(\mathrm{GaN})$ and nanoheterojunction $(\mathrm{InN})$ nanorods on one-dimensional GaN nanowire substrates. Adv. Funct. Mater. 2004, 14, 233-237.

[14] Wang, Z. L.; Kong, X. Y.; Zuo, J. M. Induced growth of asymmetric nanocantilever arrays on polar surfaces. Phys. Rev. Lett. 2003, 91, 185502.

[15] Wang, Z. L.; Kong, X. Y.; Ding, Y.; Gao, P. X.; Hughes, W. L.; Yang, R. S.; Zhang, Y. Semiconducting and piezoelectric oxide nanostructures induced by polar surfaces. Adv. Funct. Mater. 2004, 14, 943-956.

[16] Park, J. H.; Choi, H. J.; Choi, Y. J.; Sohn, S. H.; Park, J. G. Ultrawide ZnO nanosheets. J. Mater. Chem. 2004, 14, 35-36.

[17] Zhang, Y. H.; Liu, J.; Liu, T.; You, L. P.; Li, X. G. Supersaturation-controlled synthesis of two types of single-sided $\mathrm{ZnO}$ comb-like nanostructures by thermal evaporation at low temperature. J. Cryst. Growth 2005, 285, 541-548.

[18] Peng, Q.; Dong, Y. J.; Deng, Z. X.; Li, Y. D. Selective synthesis and characterization of CdSe nanorods and fractal nanocrystals. Inorg. Chem. 2002, 41, 5249-5254.

[19] Kuang, D. B.; Xu, A. W.; Fang, Y. P.; Liu, H. Q.; Frommen, C.; Fenske, D. Surfactant-assisted growth of novel PbS dendritic nanostructures via facile hydrothermal process. Adv. Mater. 2003, 15, 1747-1750.

[20] Wang, D.; Yu, D. B.; Shao, M. W.; Liu, X. M.; Yu, W. C.; Qian, Y. T. Dendritic growth of PbS crystals with different morphologies. J. Cryst. Growth 2003, 257, 384-389.

[21] Cheng, Y.; Wang, Y. S.; Chen, D.; Bao, F. Evolution of single crystalline dendrites from nanoparticles through oriented attachment. J. Phys. Chem. B 2005, 109, 794798.

[22] Qin, A. M.; Fang, Y. P.; Zhao, W. X.; Liu, H. Q.; Su, C. $Y$. Directionally dendritic growth of metal chalcogenide crystals via mild template-free solvothermal method. J. Cryst. Growth 2005, 283, 230-241.

[23] Zhu, J. P.; Yu, S. H.; He, Z. B.; Jiang, J.; Chen, K.; Zhou, X. Y. Complex PbTe hopper (skeletal) crystals with high hierarchy. Chem. Commun. 2005, 5802-5804.

[24] Kanaras, A. G.; Sonnichsen, C.; Liu, H. T.; Alivisatos, A. P. Controlled synthesis of hyperbranched inorganic nanocrystals with rich three-dimensional structures. Nano Lett. 2005, 5, 2164-2167.

[25] Naravanaswamy, A.; Xu, H. F.; Pradhan, N.; Peng, X. G. Crystalline nanoflowers with different chemical compositions and physical properties grown by limited ligand protection. Angew. Chem. Int. Ed. 2006, 45, 5361-5364.

\section{国圈: Springer}


[26] Xiao, J. P.; Xie, Y.; Tang, R.; Chen, M.; Tian, X. B. Novel ultrasonically assisted templated synthesis of palladium and silver dendritic nanostructures. Adv. Mater. 2001, 13, 1887-1891.

[27] Ni, Y. H.; Liu, H. J.; Wang, F.; Liang, Y. Y.; Hong, J. M.; $\mathrm{Ma}, \mathrm{X}$; $\mathrm{Xu}, \mathrm{Z}$. Shape controllable preparation of PbS crystals by a simple aqueous phase route. Cryst. Growth Des. 2004, 4, 759-764.

[28] Cölfen, H.; Mann, S. Higher-order organization by mesoscale self-assembly and transformation of hybrid nanostructures. Angew. Chem. Int. Ed. 2003, 42, 23502365.

[29] Shi, H. T.; Qi, L. M.; Ma, J. M.; Cheng, H. M.; Zhu, B. Y. Synthesis of hierarchical superstructures consisting of $\mathrm{BaCrO}_{4}$ nanobelts in catanionic reverse micelles. Adv. Mater. 2003, 15, 1647-1651.

[30] Liu, B.; Yu, S. H.; Li, L. J.; Zhang, Q.; Zhang, F.; Jiang, K. Morphology control of stolzite microcrystals with high hierarchy in solution. Angew. Chem. Int. Ed. 2004, 43, 4745-4750.

[31] Zhang, X.; Xie, Y.; Xu, F.; Tian, X. B. Growth of $\mathrm{BaWO}_{4}$ fishbone-like nanostructures in w/o microemulsion. J. Colloid Interface Sci. 2004, 274, 118-121.

[32] Sounart, T. L.; Liu, J.; Voigt, J. A.; Hsu, J. W. P.; Spoerke, E. D.; Tian, Z.; Jiang, Y. B. Sequential nucleation and growth of complex nanostructured films. Adv. Funct. Mater. 2006, 16, 335-344.

[33] Zhang, T. R.; Dong, W. J.; Keeter-Brewer, M.; Konar, S.; Njabon, R. N.; Tian, Z. R. Site-specific nucleation and growth kinetics in hierarchical nanosyntheses of branched ZnO crystallites. J. Am. Chem. Soc. 2006, 128, 10960-10968.

[34] Sanchez, C.; Arribart, H.; Guille, M. M. G. Biomimetism and bioinspiration as tools for the design of innovative materials and systems. Nat. Mater. 2005, 4, 277-288.

[35] Schwenzer, B.; Roth, K. M.; Gomm, J. R.; Murr, M.; Morse, D. E. Kinetically controlled vapor-diffusion synthesis of novel nanostructured metal hydroxide and phosphate films using no organic reagents. J. Mater. Chem. 2006, 16, 401-407.

[36] Kisailus, D.; Schwenzer, B.; Gomm, J.; Weaver, J. C.; Morse, D. E. Kinetically controlled catalytic formation of zinc oxide thin films at low temperature. J. Am. Chem. Soc. 2006, 128, 10276-10280.

[37] Brutchey, R. L.; Morse, D. E. Template-free, lowtemperature synthesis of crystalline barium titanate nanoparticles under bio-inspired conditions. Angew. Chem. Int. Ed. 2006, 45, 6564-6566.

[38] Vesselinov, I. Dendritic growth of lead molybdate in aqueous solutions. J. Cryst. Growth 1996, 167, 725-728.

[39] Yang, D.; Qi, L. M.; Ma, J. M. Well-defined star-shaped calcite crystals formed in agarose gels. Chem. Commun. 2003, 1180-1181.

[40] Oaki, Y.; Imai, H. Experimental demonstration for the morphological evolution of crystals grown in gel media. Cryst. Growth Des. 2003, 3, 711-716.

[41] Zeng, H. C.; Chong, T. C.; Lim, L. C.; Kumagai, H.; Hirano, M. Pseudo-dendritic growth in lead molybdate single crystal by Czochralski technique. J. Cryst. Growth 1994, 140, 148-156.

[42] Zhang, H.; Davison, W. Diffusional characteristics of hydrogels used in DGT and DET techniques. Anal. Chim. Acta 1999, 398, 329-340.

[43] Wu, Z. C.; Pan, C.; Yao, Z. Y.; Zhao, Q. R.; Xie, Y. Largescale synthesis of single-crystal double-fold snowflake $\mathrm{Cu}_{2} \mathrm{~S}$ dendrites. Cryst. Growth Des. 2006, 6, 1717-1719.

[44] Hoyt, J. J.; Asta, M.; Karma, A. Atomistic and continuum modeling of dendritic solidification. Mat. Sci. Eng. R. 2003, 41, 121-163.

[45] Tian, Z. R. R.; Liu, J.; Voigt, J. A.; Xu, H. F.; McDermot, M. J. Dendritic growth of cubically ordered nanoporous materials through self-assembly. Nano Lett. 2003, 3, 89-92.

[46] Wen, X.; Xie, Y. T.; Mak, W. M. C.; Cheung, K. Y.; Li, X. Y.; Renneberg, R.; Yang, S. Dendritic nanostructures of silver: Facile synthesis, structural characterizations, and sensing applications. Langmuir 2006, 22, 4836-4842.

[47] Cademartiri, L.; Bertolotti, J.; Sapienza, R.; Wiersma, D. S.; von Freymann, G.; Ozin, G. A. Multigram scale, solventless, and diffusion-controlled route to highly monodisperse PbS nanocrystals. J. Phys. Chem. B 2006, 110, 671-673.

[48] Meakin, P. Fractal, Scaling and Growth Far from Equilibrium; Cambridge University Press: New York, 1998.

[49] Xie, D. T.; Wu, J. G.; Xu, G. X.; Qi, O. Y.; Soloway, R. D.; Hu, T. D. Three-dimensional periodic and fractal precipitation in metal ion-deoxycholate system: A model for gallstone formation. J. Phys. Chem. B 1999, 103, 8602-8605.

[50] Grier, D. G.; Allen, K.; Goldman, R. S.; Sander, L. M.; Clarke, R. Superlattices and long-range order in electrodeposited dendrites. Phys. Rev. Lett. 1990, 64, 2152-2155. 